\title{
Authentication of Gold Products by Nuclear Methods
}

\author{
A FEASIBILITY STUDY ON GOLD COINS AND JEWELLERY
}

\author{
A.S.M. de Jesus \\ Nuclear Physics Department, Atomic Energy Corporation of South Africa Limited, Pelindaba, South Africa.
}

\begin{abstract}
The falsification of valuable gold items is an ever present threat to the authenticity of gold
products in general: Concomitant with this, there is a continuous search for reliable, practical and cost-effective means of identifying such forgeries. The possible techniques are reviewed in this article, and work on promising methods in the autbor's laboratory described.
\end{abstract}

The problem of authenticating gold items, particularly coins and jewellery, certainly goes back thousands of years. The early falsifications were crude but so were the testing methods available. Forgeries today can be very sophisticated. Considerable strides have been made in the areas of alloying, plating and other metallurgical technologies, and, as a spinoff from these technologies, an active 'industry' of forging of gold articles has come to the fore.

There is at the present time a whole family of analytical techniques which permit very accurate determinations of the gold content (caratage) of gold articles but most of these techniques involve either the destruction of a portion of the article as part of the analytical procedure, or the analysing of only a limited portion of the article, for instance its surface. Because this is intrinsically a practical problem, any possible solution to it must also be practical. Thus, the need that exists is for a fairly rapid testing system or device capable of obeying the following criteria:

(i) it must be non-destructive;

(ii) it must determine the gold content of the article as a whole within an acceptable accuracy;

(iii) its operation must be fairly simple, and

(iv) it must be cost-effective.

Because nuclear techniques as applied to elemental analysis have a high degree of specificity, are non-destructive and permit the availability of results within a relatively short time, it wasconsidered appropriate to investigate, select and evaluate nuclear techniques with a view to finding a method suitable for authenticating gold items. In principle, several such techniques are suitable (1-9) but constraints such as those imposed by the time taken by the measurement, negligible residual activity within a relatively short time and other physical considerations are likely to preclude the use of the majority of such methods. They will nevertheless be briefly considered. Furthermore, a clear distinction must be made between gold coins, such as Krugerrands, which have a uniform shape and mass, and jewellery and other gold objects of various shapes and sizes. Treatment of the latter case is complicated mainly by geometrical effects and would logically therefore only be considered in methods found to be suitable for coins.

\section{Transmission of Electromagnetic Radiation}

The transmission of electromagnetic radiation through a medium is a function of the energy of the incident radiation, mean atomic number and thickness of the medium. The method is, therefore, not unique for element identification since more than one combination of elements can be selected to produce the same transmission.

Assuming that attempts were made to substitute tungsten for some of the gold in, for instance, a Krugertand (both gold and tungsten have a specific gravity of $19.3 \mathrm{~g} / \mathrm{cm}^{3}$ ), it could be contemplated to use the difference between the K-absorption edges of the two metals. $\mathrm{K}_{\mathrm{ab}}$ of gold is $80.71 \mathrm{keV}$, while that of tungsten is $69.51 \mathrm{keV}$, so that the attenuation of an X-ray beam of energy between these two energies will be fairly sensitive to the presence of tungsten. This is illustrated in Table I, which shows the expected transmission for incident X-rays of $75 \mathrm{keV}$, given that a certain percentage of the gold has been replaced with tungsten.

It can also be seen that transmission is very low and that approximately $9 \times 10^{8} \mathrm{X}$-rays of $75 \mathrm{keV}$ must be incident on the gold coin per second, in order to obtain a statistical precision of 1 per cent in a counting time of one minute, at the 20 per cent tungsten level. For a 10 per cent precision an effective beam intensity of $9 \times 10^{6} \mathrm{X}$-rays per second would be required. To achieve these precisions, radioactive sources of $30 \mathrm{Ci}$ and $0.3 \mathrm{Ci}^{*}$, respectively, emitting no other radiation capable of interfering with the measurement, would be needed. However, neither is a suitable radioactive source emitting gamma rays in the energy range of $69.5-80.7 \mathrm{keV}$ available commercially nor can it be produced.

In theory, it is possible to excite the characteristic $\mathrm{KX}$-rays of lead $(72.8-87.3 \mathrm{keV})$ and use the $\mathrm{K}_{\alpha} \mathrm{X}$-rays after filtration of the $\mathrm{K}_{\beta} \mathrm{X}$ -

\section{$* 1$ Curie $(\mathrm{Ci}) \equiv 3.7 \times 10^{10}$ disintegrations per second}

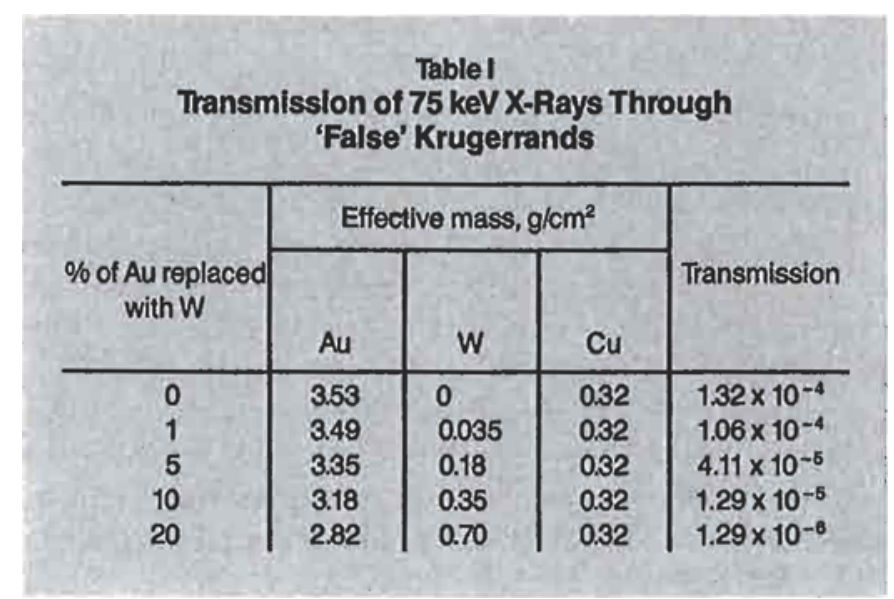


rays with a suitable element such as mercury. This could be done by means of an X-ray tube operated at about $130 \mathrm{kV}$ and very high tube current. But again, it is expected that as a result of the very low conversion coefficient on the lead target, insufficient intensity of $75 \mathrm{keV}$ X-rays would be available for practical utilization of this method. Reliable information on the viability of the method would have to be obtained experimentally. No residual activity will be formed.

\section{Scattering of Electromagnetic Radiation}

Compton and resonant scattering were considered. The intensity of Compton scattered radiation is sensitive to the mean atomic number (and density) of the scattering medium. The method will, however, only become practical when the variations are fairly large, which, very likely, would not be the case with, for example, forged gold coins. Again, the method is not unique for gold. The option is not considered a viable method of detection.

In principle, energy levels of isotopes can be resonantly excited by gamma rays of energy equal to that of the specific level and compatible with its width. Typical widths of non-isomeric levels are of the order of $5 \times 10^{-5} \mathrm{eV}$, but due to the thermal motion of nuclei they are increased to about $1 \mathrm{eV}(10)$. For this reason, and others which need not be elaborated upon, the cross-section for resonant scattering is in general extremely low. Levels in a few light nuclei have been excited by some workers (11-13) but sources of several kilocuries and counting times of some 30 hours were used. This option is further discussed later under inelastic scattering of gamma radiation.

\section{X-Ray Fluorescence Analysis}

It is practical and easy to excite the characteristic X-rays of gold and various other elements by means of low-energy gamma radiation such as that emitted by ${ }^{109} \mathrm{Cd}$ and ${ }^{37} \mathrm{Co}$. However, owing to the very high mass absorption coefficient of gold the method is suitable only for surface analysis, or, at most, down to a depth of about $100 \mu \mathrm{m}$. This method may, therefore, be discarded as being unsuitable for the purpose which we are considering here.

\section{Neutron Activation Analysis (NAA)}

Gold can be easily detected by means of NAA as a result of the high cross-section or probability ( $\sigma=99$ barns) for the reaction ${ }^{197} \mathrm{Au}(\mathrm{n}, \gamma){ }^{198} \mathrm{Au}$ for thermal neutrons. ${ }^{198} \mathrm{Au}$ decays with a half-life of 2.7 days. A Krugerrand gold coin was, therefore, irradiated for 5 minutes with neutrons emitted by a $7 \mathrm{Ci}^{241} \mathrm{Am} / \mathrm{Be}$ source, with the coin in contact with the source. The resulting $411 \mathrm{keV}$ gamma rays emitted by ${ }^{198} \mathrm{Au}$ were counted by means of a $75 \times 75 \mathrm{~mm}$ sodium iodide detector. Analysis of the data permitted the calculation of the approximate statistical precision which will be obtained under a few irradiation and counting conditions using a $5 \mathrm{Ci}^{241} \mathrm{Am} / \mathrm{Be}$ source. This is shown in Table II.

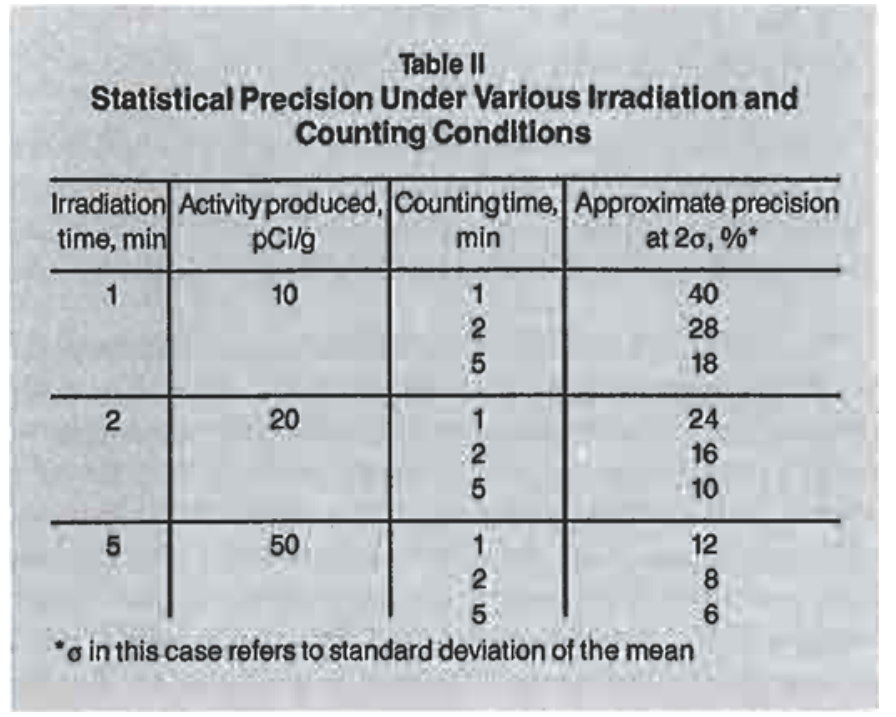

The specific activity of the Krugerrand after the 5 minute irradiation is estimated at $50 \mathrm{pCi} / \mathrm{g}$. This may be compared with the specific activity of ordinary soil, which is of the order of $20 \mathrm{pCi} / \mathrm{g}$. For evaluation in perhaps a better perspective it may be recalled that the maximum permissible concentration of ${ }^{198} \mathrm{Au}$ in drinking water, as previously recommended by the International Commission on Radiological Protection (14), is $10000 \mathrm{pCi} / \mathrm{l}$. This method is specific for gold and the residual activity is negligible as it cannot be detected by most conventional radiation detectors. It could be considered as a viable detection method and the possibility of extending it to the authentication of gold jewellery was also investigated.

A small experiment was conducted whereby the absorption of thermal neutrons in gold was experimentally measured. For this purpose a stack of five 24-carat discs, protected on their sides, except one of the circular sides, with $1 \mathrm{~mm}$ thick cadmium sheet was exposed to a flux of thermal neutrons. The open side faced the source. Since thermal neutrons could enter the stack only through its open end, this permitted the observation of the absorption of thermal neutrons in gold as a function of depth. The results, displayed graphically in Figure 1, show that the thermal neutron flux is reduced by as much as 45 per cent after only $1 \mathrm{~mm}$ of gold.

A second experiment was performed whereby three pieces of 24 carat gold wire of identical length $(2 \mathrm{~cm})$ and thickness $0.5,1$ and $3 \mathrm{~mm}$, respectively, were simultaneously irradiated with the same integrated flux. By normalising the counts obtained for each wire thickness to the same mass of gold the extent of loss in count rate due to wire thickness could be determined. From the results, shown graphically in Figure 2 , it can readily be seen that an increase in wire diameter from $0.5 \mathrm{~mm}$ to 1 and $3 \mathrm{~mm}$ gives rise to a loss in count rate of 26 and 64 per cent, respectively. Some of the loss could be due to self-attenuation of the $411 \mathrm{keV}$ gamma ray in gold, but the 
mechanism mainly responsible for such loss seems to be the absorption of neutrons in gold.

From the above results it is evident that the drastic absorption of thermal neutrons in gold has serious implications on the assaying of gold objects of varying thickness. As in the previous case, the levels of residual activity are negligible.

\section{Activation by Inelastic Scattering of Gamma Radiation}

The radionuclide ${ }^{107 \mathrm{~m}} \mathrm{Au}$ can be formed by inelastic scattering of gamma radiation according to the reaction ${ }^{197} \mathrm{Au}\left(\gamma, \gamma^{1}\right)^{197 \mathrm{~m}} \mathrm{Au}$. Its short half-life of only $7.8 \mathrm{~s}$ makes it very suitable for rapid analysis of gold but the reaction cross-section is only about $4 \mu \mathrm{b}$ for $6 \mathrm{MeV}$ gamma rays. Therefore, gamma fluxes such as those obtained with bremsstrahlung spectra from electron accelerators are indicated. Recent work carried out at our laboratory showed that a $60 \mathrm{~s}$ irradiation of $150 \mathrm{mg}$ of gold with gamma rays produced by $8 \mathrm{MeV}$ electrons resulted in 9000 counts in $30 \mathrm{~s}$, after a cooling time of $10 \mathrm{~s}$.

Extrapolating to the case of a Krugerrand coin, the number of counts immediately after irradiation would be approximately 4.5 million. It is evident that a smaller accelerator using an electron current of some $0.2 \mu \mathrm{A}$ would be quite sufficient for a statistical precision of 1 per cent. For a precision of 10 per cent a current of only $2 \mathrm{nA}$ would be required. Should there be any residual activity, it is expected that it will be negligibly small.

In spire of the unlikelihood that a radioisotopic gamma source could be used for the activation of gold, a Krugerrand coin was exposed for 1 minute to the flux of a $50000 \mathrm{Ci}^{60} \mathrm{Co}$ source, with the coin practically in contact with the cobalt elements. This was immediately followed by gamma spectrometric counting. Not only was there no identification of the $279 \mathrm{keV}$ peak from the decay of ${ }^{197 \mathrm{~m}} \mathrm{Au}$ but also no measurable activity emitted by the coin was detected. Similar tesults were obtained with a $200 \mathrm{mCi}$ source of ${ }^{124} \mathrm{Sb}$, which has a more energetic gamma spectrum than ${ }^{60} \mathrm{Co}$.

\section{Activation by Inelastic Scattering of Fast Neutrons}

Inelastic scattering of fast neutrons on gold $\left({ }^{197} \mathrm{Au}\left(\mathrm{n}, \mathrm{n}^{\prime}\right)^{197 \mathrm{~m}} \mathrm{Au}\right)$ leads to the formation of the same radionuclide, namely ${ }^{107 \mathrm{~m}} \mathrm{Au}$, as in the scattering of gamma radiation. However, in this case one is dealing with a fairly high reaction cross-section (about $0.5 \mathrm{~b}$ for $\mathrm{E}_{\mathrm{n}}=3 \mathrm{MeV}$ ), which renders the situation considerably mote favourable for the rapid analysis of gold.

A Krugertand coin was therefore irradiated for $30 \mathrm{~s}$ with neutrons from a $7 \mathrm{Ci}^{241} \mathrm{Am} / \mathrm{Be}$ source, with the coin virtually in physical contact with the source. Counting started $8 \mathrm{~s}$ after termination of the irradiation and was carried out over $30 \mathrm{~s}$ by means of a suitable detector duly shielded. Approximately 1500 nett counts above a background of 18 counts were obtained in the $279 \mathrm{keV}$ peak during the counting period. The statistical precision under these counting conditions is approximately 5 per cent for a 2 standard deviations criterion.

The geometry can be considerably improved by having a sodium

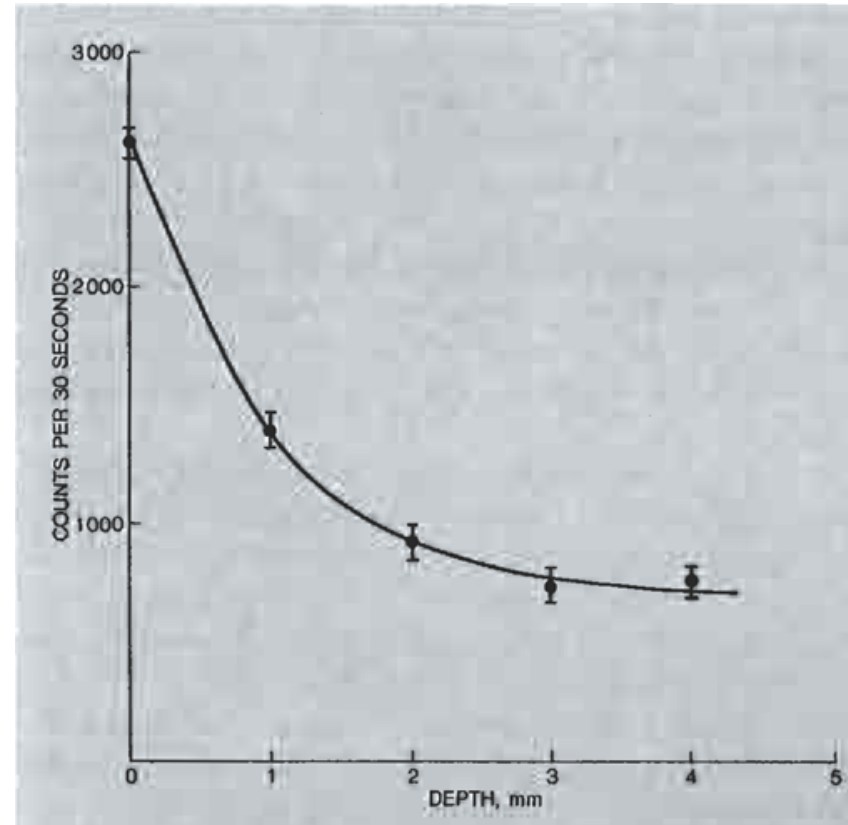

Fig. 1 Activity distribution of $411 \mathrm{keV}$ gamma mys as a function of depth in gold dise stack

Fig. 2 Variation in $411 \mathrm{keV}$ count rate due to wire thickness

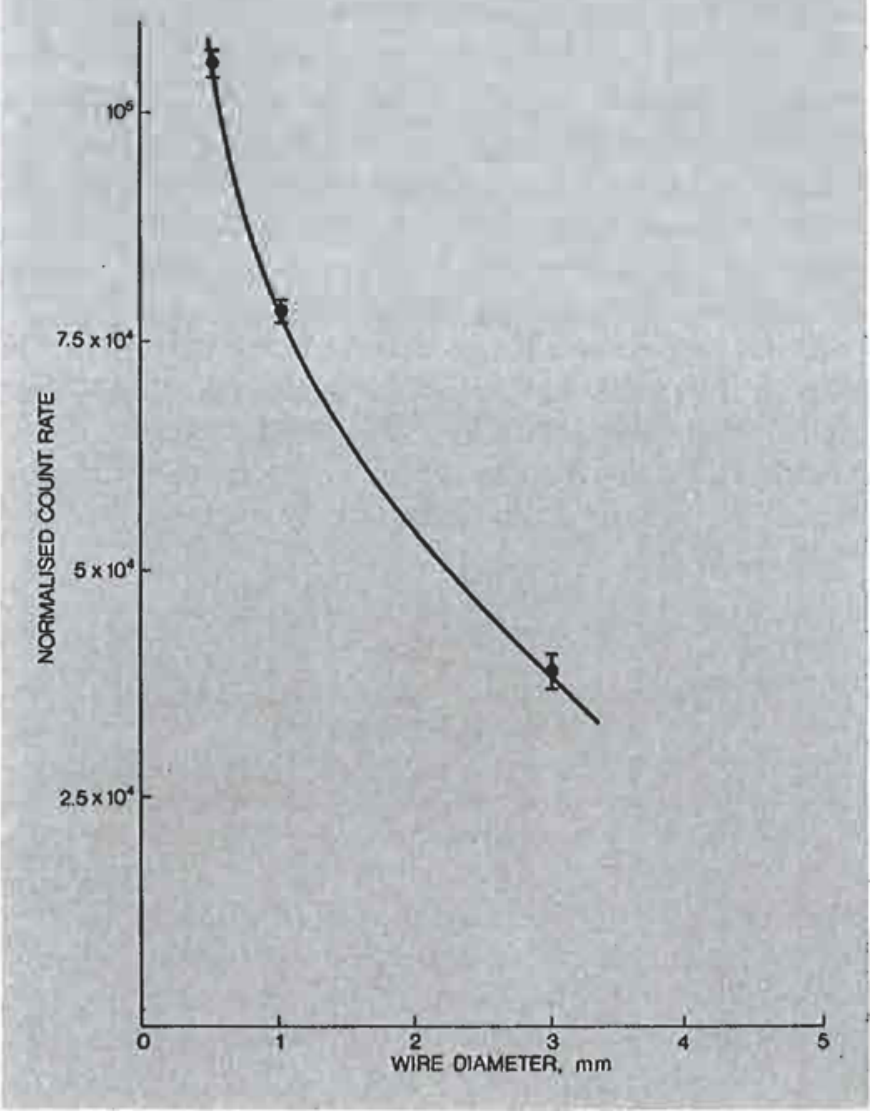


iodide crystal specially designed for this purpose; a stronger neutron source can be used, and a system can be designed to enable counting to start within about one second after termination of the irradiation. Table III provides a rough estimation of the activity formed and the statistical precision of each measurement under such improved conditions.

The evidence shows that this method is practical, viable and that there is no residual activity from ${ }^{198} \mathrm{Au}$. The alternative of using a neutron generator to induce the same nuclear reaction was, therefore, not pursued as the costs involved could be an order of magnitude higher.

As with neutron activation analysis, the method of inelastically scattering fast neutrons was further investigated for use in the assaying of pieces of jewellery. The parameters investigated were the absorption and scattering of fast neutrons by gold, the selfattenuation of gamma radiation in gold and the influence of sample shape, irradiation and counting geometries.

Two experimental arrangements, one for handling disc samples and the other for samples of irregular and varied shapes, were used. Both consisted of an irradiation chamber connected by a $4 \mathrm{~m}$ conduit to a counting chamber. A source of $3 \mathrm{Ci}^{241} \mathrm{Am}-\mathrm{Be}$ was utilised. For disc samples a 50 × $50 \mathrm{~mm}$ planar sodium iodide detector was used and the sample transport mechanism relied on gravity. With other samples the detector wasa $75 \times 75 \mathrm{~mm}$ well-type sodium iodide crystal and the propulsion mechanism made use of compressed air. In both cases the irradiation as well as the counting chambers allowed various geometries to be used. In all measurements the time elapsed between the end of the irradiation and the start of counting (cooling time) was approximately one second. Its measurement was carried out accurately by means of photo-transistors strategically placed, and due correction for decay during cooling and counting times was applied.

All disc samples were $22 \mathrm{~mm}$ in diameter and $1 \mathrm{~mm}$ thick. The other samples consisted of wire of thicknesses $0.5,1.2$ and $3 \mathrm{~mm}$, cut into various lengths and given various shapes. Gold of 9-, 18-and 24-carat was employed. Irradiation and counting times of $30 \mathrm{seach}$ were used in all cases as this was found to be optimal for the halflife of ${ }^{197 m} \mathrm{Au}$.

Table III
Expected Statistical Preclsion Through Inelastic
Scattering of Neutrons

\section{Absorption and Scattering of Fast Neutrons}

Given that pieces of jewellery will vary in thickness, it was considered sensible to investigate to what extent neutron activation of the gold would vary as a result of neutron absorption in gold. A stack of five 24-carat discs irradiated perpendicularly to its circular surface, at a distance of $2 \mathrm{~cm}$ from the source, was used for this purpose. The results, displayed graphically in Figure 3, show a (regular) decrease in activity as a function of depth. A quadratic fit to the experimental data indicated that the decrease is proportional to the inverse square of the distance of each disc from the source. A similar pattern was obtained when stacks of 18- and 9-carat discs were used.

In order to cross-validate the previous observations, a single disc was irradiated under identical conditions and at constant distance $(2.5 \mathrm{~cm})$ from the source, but with a varying number of similar discs interposed between the target-disc and the source. Any attenuation of the neutron flux caused by the interposed discs would be reflected in the activity generated in the target-disc. The results, shown in Figure 4, again indicate fairly conclusively that neutron absorption is very small. The statistical uncertainty is about 4 per cent and the difference between maximum and minimum counts is

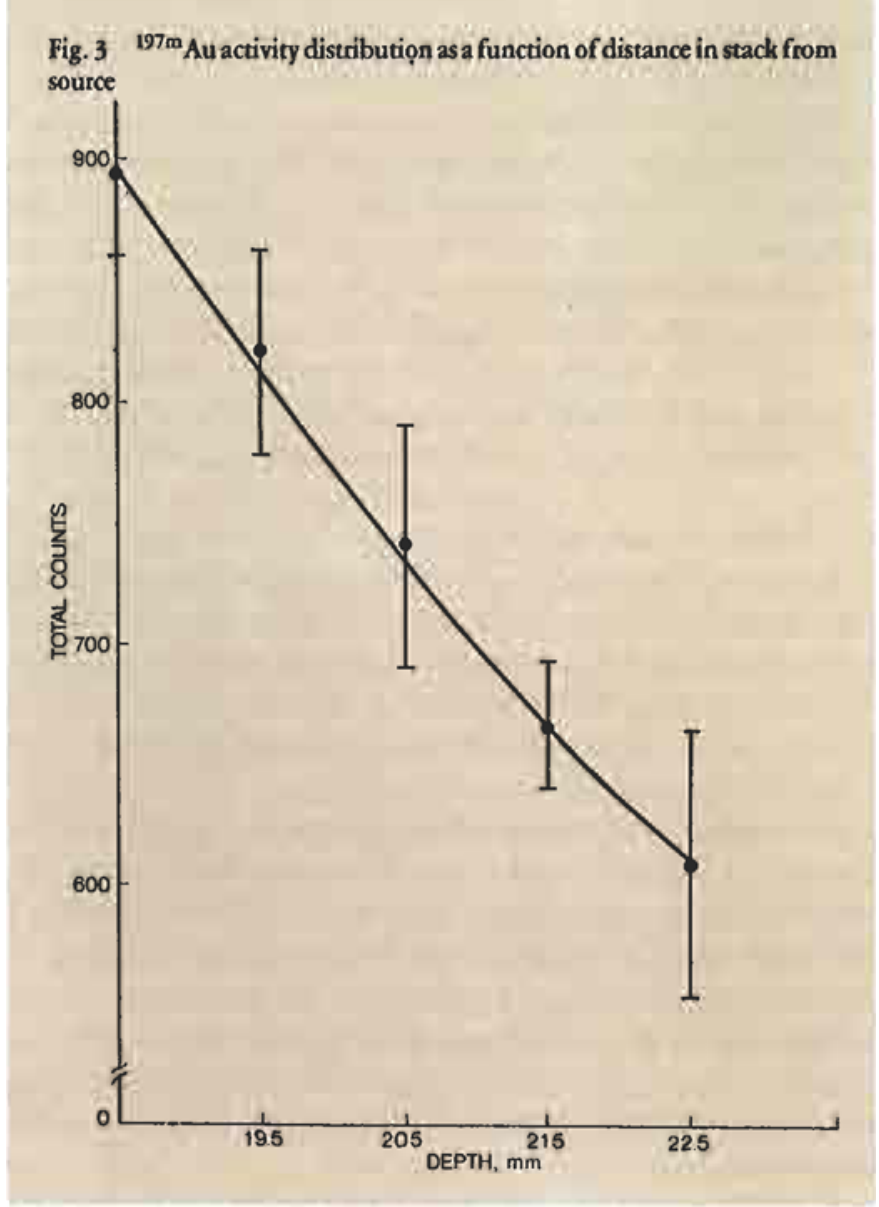




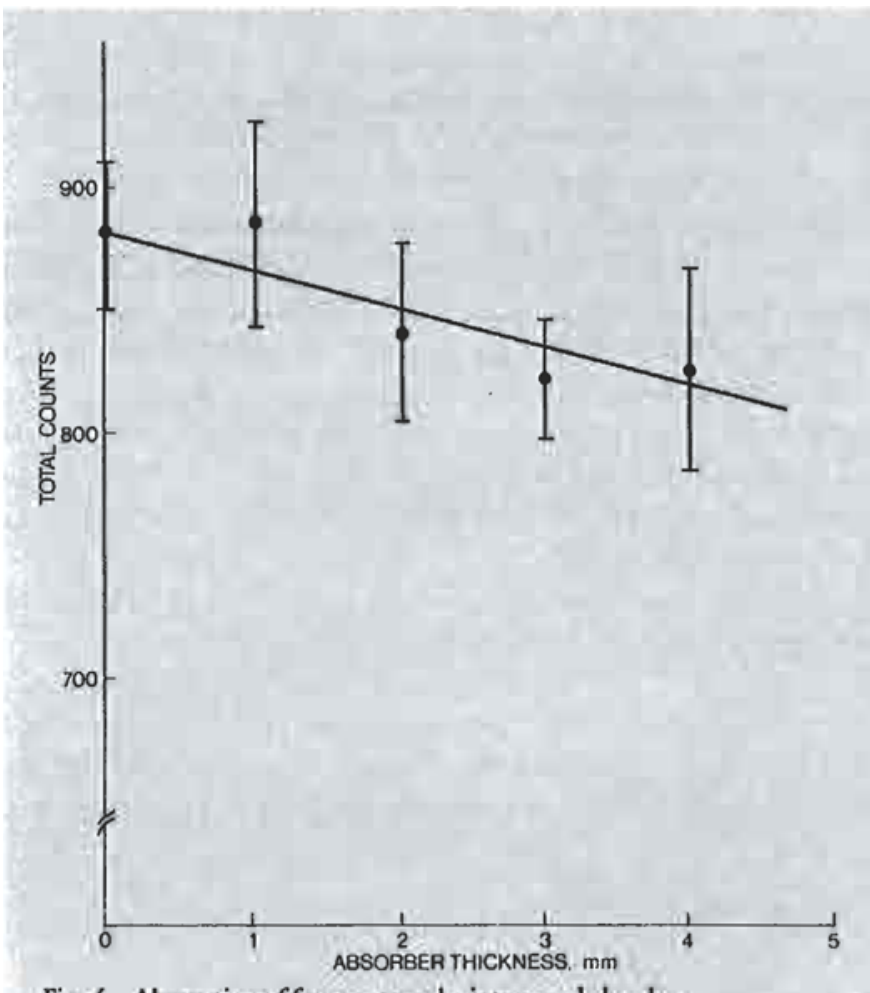

Fig. 4 Absorption of fast neutrons by interposed absorbers

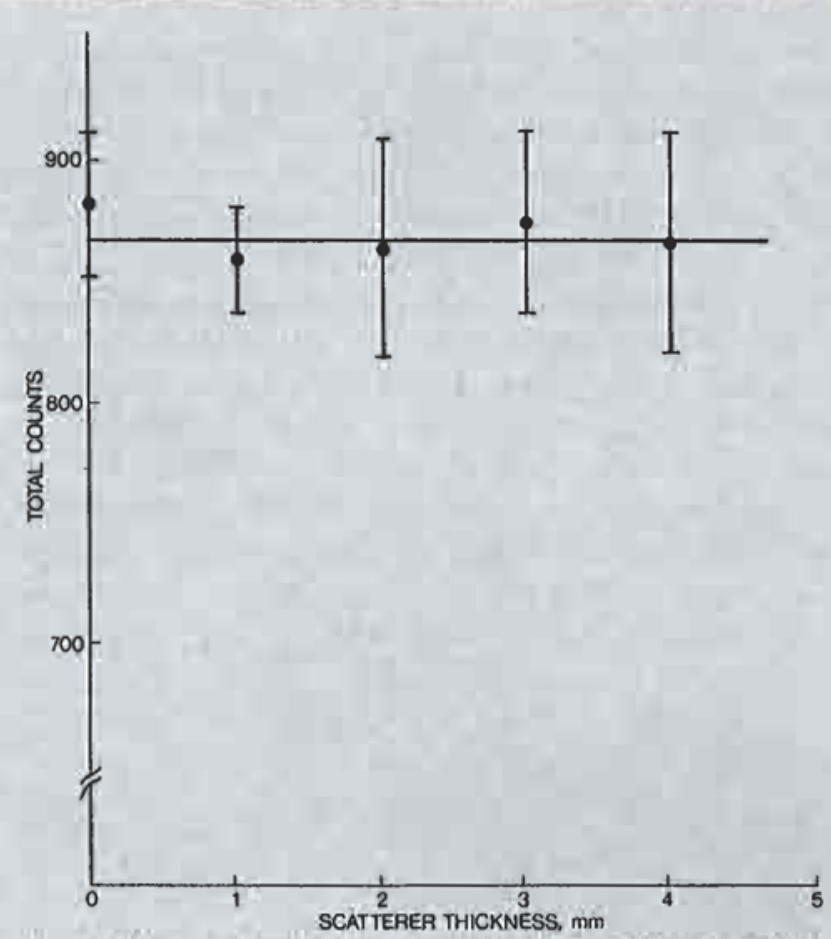

Fig. 5 Influence of backscattered neutrons on the induced activity in the target dise approximately 7 per cent.

Although not expected to be large, the influence of scattered neutrons on the amount of activity generated was also investigated. For this purpose a single disc was irradiated under similar conditions but instead of interposing discs between target-disc and source, these were positioned bebind the target-disc. This geometry permitted the measurement of the contribution of backscattered neutrons to the induced activity in the target-disc. As shown in Figure 5 , no such effect was detected.

The above observations clearly indicate that the generation of ${ }^{197 \mathrm{~m}} \mathrm{Au}$ activity is not significantly affected by the absorption and scattering of fast neutrons by gold.

\section{Self-attenuation of Gamma Radiation in Gold}

The half-value thickness of gold for the $279 \mathrm{keV}$ gamma ray is only $0.75 \mathrm{~mm}$, which means that the gamma radiation of interest will be considerably attenuated by gold. A series of experiments was carried out to assess the influence of self-attenuation of the $279 \mathrm{keV}$ gamma-ray in gold samples of various caratages.

Following irradiation, single discs and stacks of up to 5 discs of 9-, 18-and 24-carat were counted in the well-crystal. By plotting the number of counts in the $279 \mathrm{keV}$ peak against the mass of gold in the sample (see Figure 6) a distribution of points, through which a 4th-degree polynomial could be fitted was obtained. The nonlinear relationship is intuitively understood in terms of the increasing attenuation with increasing sample mass. The fact that the curve is unique for the various gold masses and that the scatter about the curve is fairly small leads to the conclusion that the caratage of discs of constant diameter is measurable.

In another experiment, wire samples of various thicknesses were chosen as they provided a very convenient way of assessing the

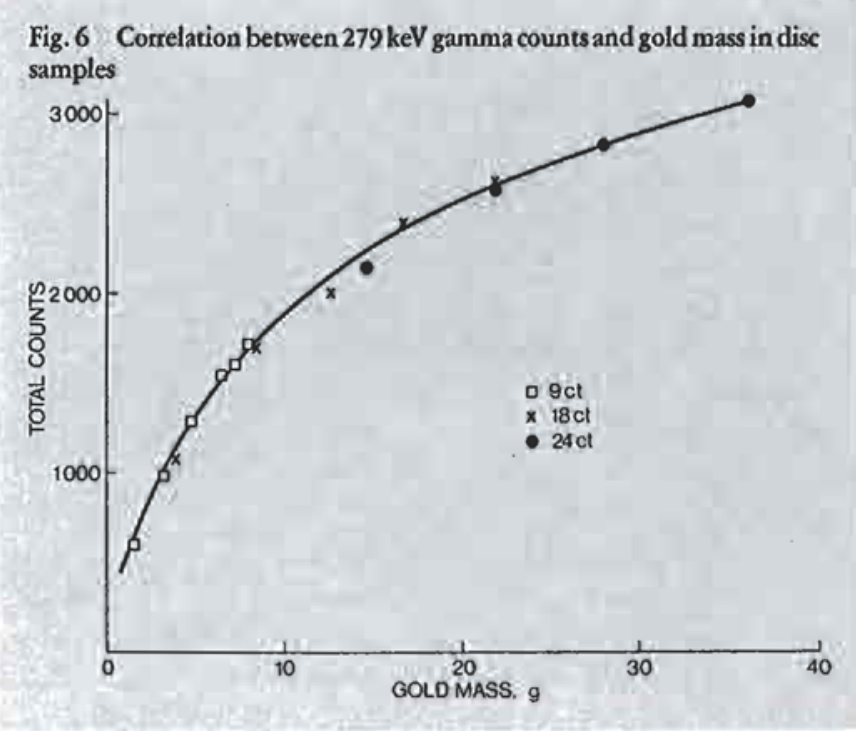


influence of self-attenuation. By using pieces of wire of the same length and caratage but different diameters, the variation in selfattenuation could readily be assessed. This variation was found to beconsiderable as can be deduced from the plots in Figure 7 . There is neither a unique curve nor could a general normalising function be found without having to revert to complex calculations which would detract from the practicality of the method.

Attempts were made at using the $67 \mathrm{keV} \mathrm{KX}$-ray of gold, which is produced by internal conversion of gamma rays. In this case the half-value thickness of gold is only $0.1 \mathrm{~mm}$ and it was thus presumed that some correlation might be found between the ratio of the counts in the $279 \mathrm{keV}$ to the $67 \mathrm{keV}$ peaks and parameters related to the wire radius. No such correlation could be established. In fact, when drawing plots for the X-rays on the same basis as those used for gamma rays, curves very closely resembling those in Figure 7 were obtained. These are shown in Figure 8.
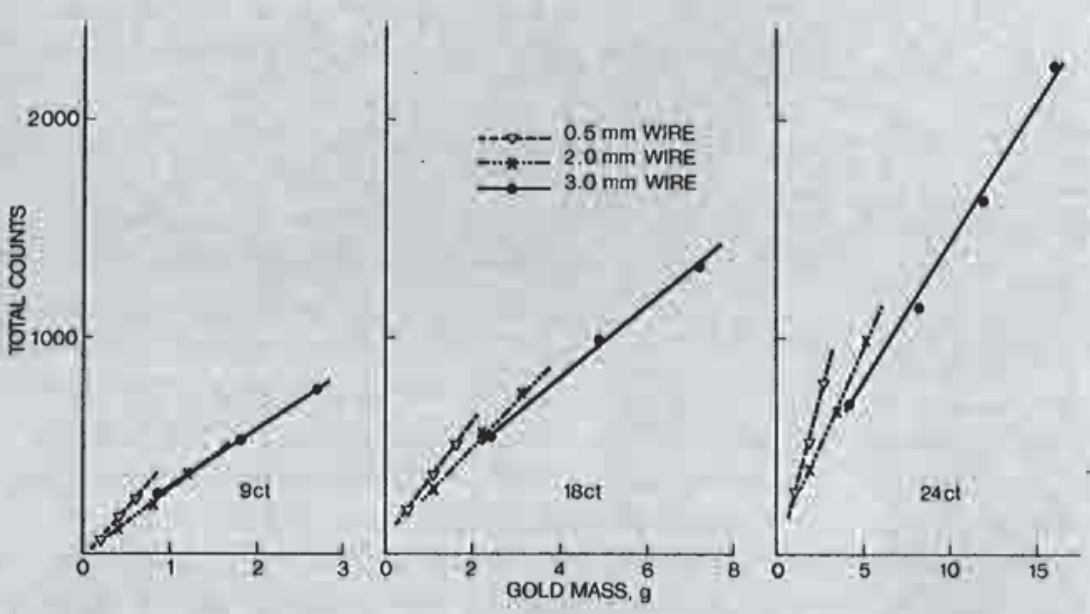

Fig. 7 Correlation between $279 \mathrm{keV}$ gamma counts and gold mass in wire samples

Fig. 8 Correlation between $67 \mathrm{keV} \mathrm{X}$-ray counts and gold mass in wire samples
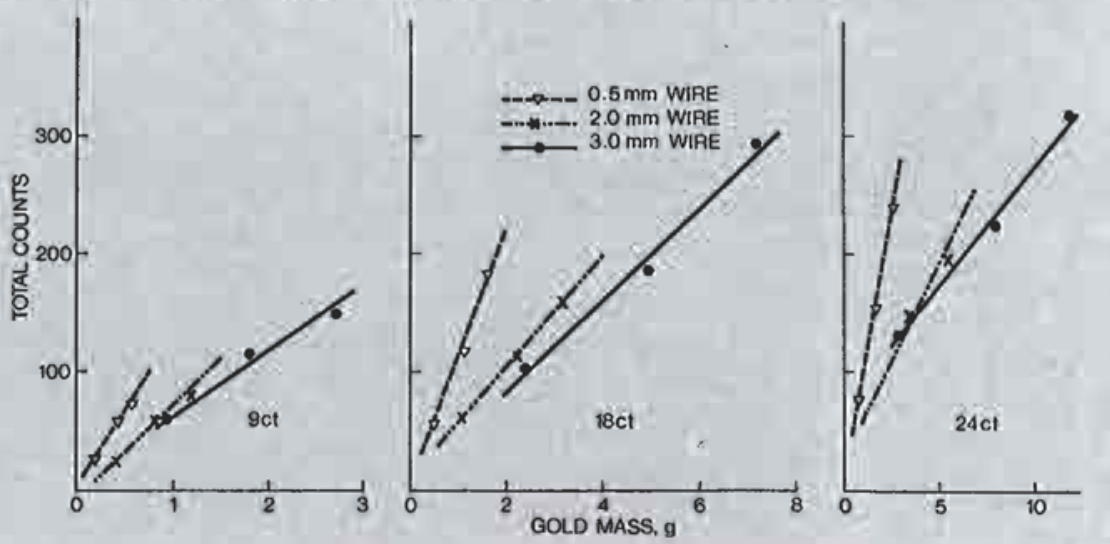

From the above experiments it may readily be deduced that the self-attenuation of the $279 \mathrm{keV}$ gamma-ray in gold is too large to permit its use in the assaying of gold items of varying thicknesses.

\section{Influence of Sample Shape}

Three pieces of 24-carat gold wire of thicknesses 1,2 and $3 \mathrm{~mm}$ were each twisted into various shapes and individually irradiated and counted for the same time. The results are given in Table IV.

It may be seen that for each wire thickness the variation in the number of counts as a result of varying shape is not significant. For each shape, the wire turns were never in close contact with one another. Should there be close contact, greater variations in the number of counts can be expected as a result of some wire turns 'obscuring' other turns.

A further observation is that whereas the three wire pieces had mass ratios of $1: 4: 9$ and surface area ratios of $1: 2: 3$ the ratios in the number of counts are $1: 2.6: 4.7$, i.e. intermediate values. On a semiquantitative basis, this is consistent with the influence of self-attenuation of the gamma rays.

\section{Influence of Irradiation and Counting Geometries}

Because both neutron flux and detector efficiency depend on the position of the sample relative to the neutron source and the detector, respectively, the importance of irradiation and counting geometries were examined.

As regards the irradiation geometry only the dependence of the flux on the lateral displacement of the sample relative to the source was investigated. Discs were used for this purpose. The results are graphically displayed in Figure 9, from which it can be seen that under the experimental conditions used, variations of $\sim 1 \mathrm{~cm}$ from optimum position can be tolerated. This was well within the reproducibility of the system.

When counting discs by means of the planar detector there is no complex counting geometry to contend with and reproducibility is easily achieved. On the other hand, when using the well-detector, it is important to know the depth in the crystal at which the counting efficiency starts decreasing. This is particularly true for objects of different and irregular shape. After irradiating a disc it was counted in the 


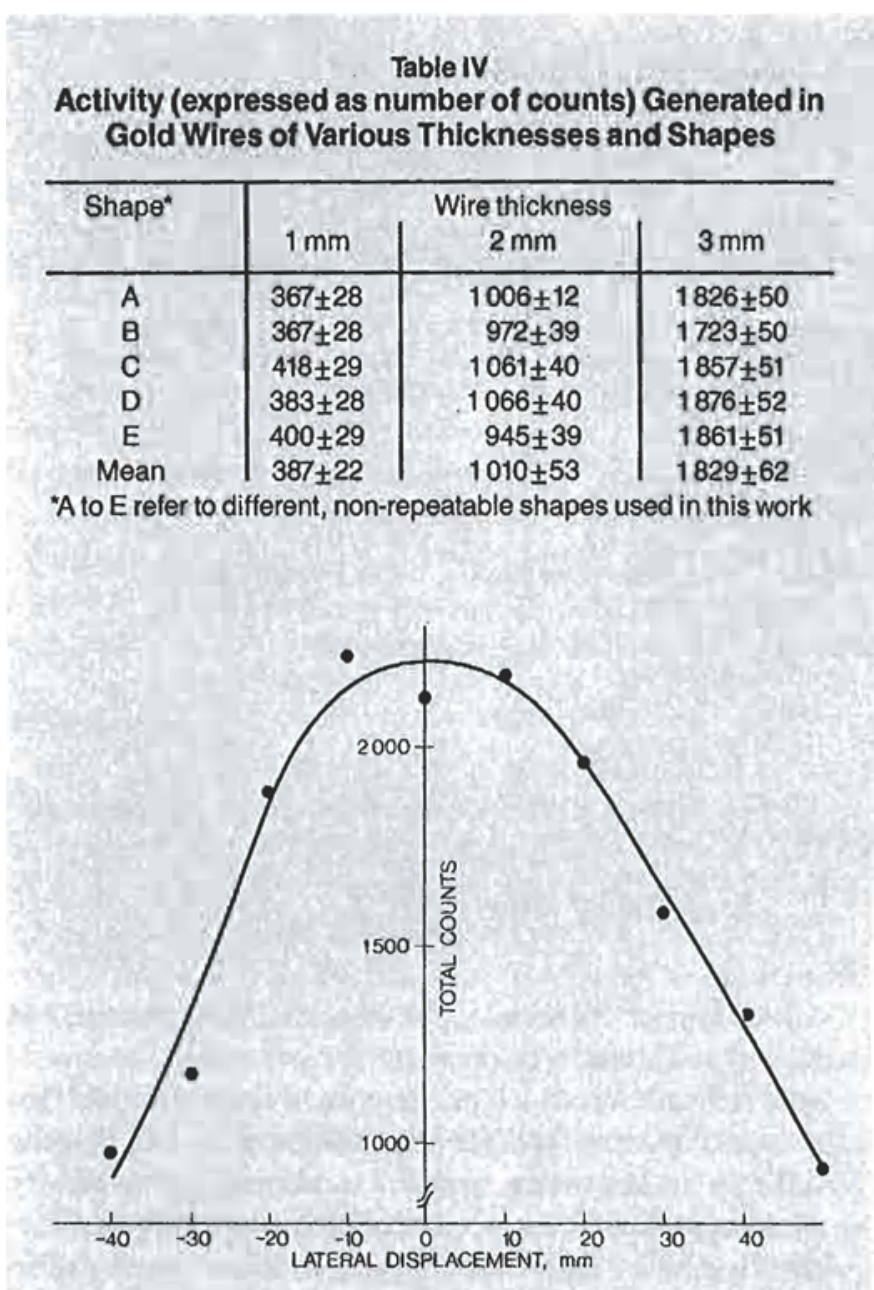

Fig. 9 Influence of lateral displacement of sample from source on neutron flux during irradiation

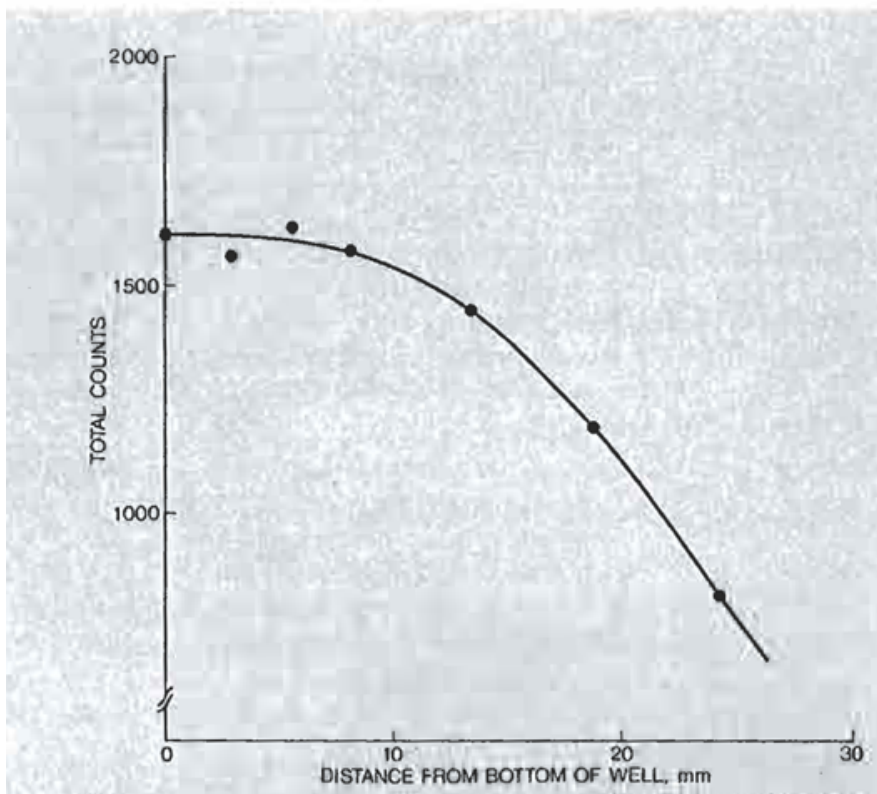

Fig. 10 Influence of sample position on the counting efficiency of the well-crystal

well-crystal but its distance from the bottom of the well was varied. The results obtained are given in Figure 10 which clearly shows that any object placed in the well with any portion of it at a distance greater than $1 \mathrm{~cm}$ from the bottom of the well will be counted with decreased efficiency.

\section{Detection Limit and Residual Activity}

Using a criterion of 3 standard deviations above background, the estimated detection limit is $\sim 0.4 \mathrm{~g}$ gold for a $3 \mathrm{Ci}^{24 \mathrm{~mm}} \mathrm{Am}$-Be source, if samples of identical shape and size are used.

Due to the very short half-life of ${ }^{17 \% m} \mathrm{Au}$ no measurable residual activity arising from this radionuclide remains after approximately

Table V

Nuclear Methodologies as Applied to the Possible Authentication of Krugerrands

\begin{tabular}{|c|c|c|c|}
\hline Method & Viability & $\begin{array}{l}\text { Specificity } \\
\text { for gold }\end{array}$ & $\begin{array}{l}\text { Residual } \\
\text { activity }\end{array}$ \\
\hline Transmission & $\begin{array}{l}\text { Uncertain. Further experimental } \\
\text { work required. Very likely impractical. }\end{array}$ & Non-specific & None \\
\hline Compton scattering & Not viable. & Non-specific & None \\
\hline XRF & $\begin{array}{l}\text { Unsuitable. Suitable for surface } \\
\text { analysis. }\end{array}$ & Specific & None \\
\hline $\begin{array}{l}\text { NAA } \\
\text { Gamma inelastic }\end{array}$ & $\begin{array}{l}\text { Could be considered. } \\
\text { Viable but expensive as it requires } \\
\text { electron accelerator. }\end{array}$ & $\begin{array}{l}\text { Specific } \\
\text { Specific }\end{array}$ & $\begin{array}{l}\text { Negligible } \\
\text { Not measured } \\
\text { but expected to } \\
\text { be negligible }\end{array}$ \\
\hline $\begin{array}{l}\text { Neutron inelastic } \\
\text { scattering }\end{array}$ & Very suitable. & Specific & Virtually none. \\
\hline
\end{tabular}
one minute following irradiation. The very short irradiation time (30s) is not sufficient to excite any measurable amount of ${ }^{198} \mathrm{Au}$ activity.

\section{Conclusion}

The main conclusions to be drawn from thisstudy are summarised in Table $V$ which covers the various nuclear analytical methods which were applied to Krugerrand coins and in Table VI which deals with the most important parameters involved in the possible assaying of jewellery pieces by neutron activation. Although these tables are self-explanatory it is useful to highlight the two main points, namely: 


\section{Table VI \\ Summary of the Influence of the Most Important Parameters on the Possible Assaying of Jewellery by Neutron Activation}

\begin{tabular}{|c|c|c|}
\hline Parameter & Observations and comments & Influence on practical viability for assaying jewellery \\
\hline \multicolumn{3}{|c|}{ A. Neutron Absorption } \\
\hline Fast Neutrons & $\begin{array}{l}\text { Absorption relatively small ( } 7 \% \text { by } 7 \mathrm{~mm} \text { of gold). Thus, variations in } \\
\text { sample thickness manageable. }\end{array}$ & Viable as regards activation. \\
\hline 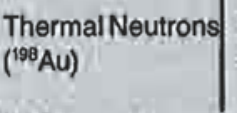 & $\begin{array}{l}\text { Strongly absorbed in gold ( } 45 \% \text { by } 1 \mathrm{~mm} \text { of gold). Thus, activation of } \\
\text { sample very sensitive to variations in sample thickness. }\end{array}$ & $\begin{array}{l}\text { Impractical for samples with varying thickness and, } \\
\text { by implication, for samples of differing sizes and } \\
\text { shapes. }\end{array}$ \\
\hline \multicolumn{3}{|c|}{ B. Gamma Attenuation } \\
\hline $\begin{array}{l}279 \mathrm{keV} \\
\text { (from }\end{array}$ & $\begin{array}{l}\text { Self-attenuation in gold considerably high (half-value } \\
\text { thickness }=0.75 \mathrm{~mm} \text { ). Therefore, observed gammas very sensitive } \\
\text { to variations in sample thickness. }\end{array}$ & $\begin{array}{l}\text { Impractical for wire samples of varying diameter and, } \\
\text { by implication, for samples of differing sizes and } \\
\text { shapes. }\end{array}$ \\
\hline $\begin{array}{l}411 \mathrm{keV} \\
\left.\text { (from }{ }^{198} \mathrm{Au}\right) \\
\text { C. Sample Shape }\end{array}$ & $\begin{array}{l}\text { Self-attenuation in gold not explicitly measured but it could be } \\
\text { considerable in thick specimens (half-value thickness }=1.75 \mathrm{~mm} \text { ). } \\
\text { Modest variations in wire samples of identical thickness do not }\end{array}$ & $\begin{array}{l}\text { Unsuitable for samples of varying thickness. } \\
\text { Irradiation and counting times relatively long. } \\
\text { Could be coped with, within limits. }\end{array}$ \\
\hline D. Geometry & influence count rate. & Possible to cone with \\
\hline \multicolumn{3}{|l|}{ E Detection Limit } \\
\hline With fast neutrons & Approximately $0.4 \mathrm{~g} \mathrm{Au}$ for a $3 \mathrm{Ci}^{241} \mathrm{Am}$-Be source. & - \\
\hline Withslowneutrons & $\begin{array}{l}\text { Approximately } 0.1 \mathrm{~g} \mathrm{Au} \text { for } \mathrm{a} 3 \mathrm{Ci}^{241} \mathrm{Am}-\mathrm{Be} \text { source and irradiation and } \\
\text { counting times of } 10 \mathrm{~min} \text {. }\end{array}$ & \\
\hline F. Residual Activity & Unmeasurable with most conventional instruments. & Does not affect viability. \\
\hline
\end{tabular}

(i) It is clear that a system based on the inelastic scattering of neutrons emitted by a ${ }^{241} \mathrm{Am} / \mathrm{Be}$ source (half-life $=433$ years) is practical and capable of authenticating gold and gold alloy coins such as Krugerrands. It is specific for gold since characteristic radiation emitted by gold itself is measured. Furthermore, a survey of the literature has revealed that no other element is likely to emit interfering gamma rays for irradiations under the same conditions. But, should an extra safety factor be desired, it is quite easy to build into the system the capability of using the $7.8 \mathrm{~s}$ half-life of ${ }^{197 m} \mathrm{Au}$ for cross-validating the determination.

A system based on NAA, where the radionuclide ${ }^{198} \mathrm{Au}$ would be used, could also be considered. It has the advantage that timing considerations are not very stringent due to the relatively long half-life (2.7 days) of ${ }^{198} \mathrm{Au}$ and, therefore, a fairly unsophisticated system would meet the practical needs. It has, however, the disadvantage that lower precisions will be achieved, higher (but still negligible) residual activity will be produced and cross-validation of the measurement based on the half-life of ${ }^{108} \mathrm{Au}$ is impractical.

The financial aspects of the above options have not been investigated but if they are to be cost-effective they would have to be used under operating conditions where high throughputs of gold coins are involved.

(ii) The feasibility study on the assaying of gold jewellery by means of nuclear methods has shown it to be impractical. The experimental evidence obtained in respeçt of the only two methods worth considering, namely activation by fast and slow neutrons, has clearly revealed that gamma self-attenuation in gold is far too large to cope, in a practical manner, with the variations in size and shape of jewellery pieces, and that this difficulty, in the case of slow-neutron activation, is compounded by the equally large absorption of slow neutrons in gold. Since the above effects are of overriding importance, the role of other parameters which are individually amendable to control becomes irrelevant.

\section{Acknowledgement}

The assistance rendered by Messrs. D.J. van der Bank and G.W.J, van der Berg with the experimental work is gratefully acknowledged. Acknowledgement is also madc to International Gold Corporation for the funding of this work.

\section{References}

1 G. Revel, Trans. Am. Nucl. Soc, 1975, 21, 25

2 P. Reimers, G.J. Lutz and C. Segebade, J. Radioanal. Chem, 1977, 39, 93-97

3 A.S.M. de Jesus andJ.K. Basson, Int.J. Appl, Radiat. Isolopes, 1977, 28, 873-883

4 F. Ozek, Radiochem. Radioanal. Lett. 1978, 35, 233-240

5 M. Poncet and C. Engelmann, Nucl. Instrum. Metbods, 1978, 149, 461-467

6 A. Veres and I. Pavlicsek, J. Radioanal. Chem., 1982, 69, 325-336

7 G. Demortier and T. Hackens, Nuch. Instrum. Methods Phys. Res., 1982, 197, 223-236

8 Z.B. Alfassi and N. Lavi, J. Radioanal. Chem., 1983, 76, 257-259

9 G. Demortier, Gold Bull., 1984, 17, 27-38

10 K. Siegbahn, 'Alphar, Beta- and Gamma-Spectrometry; Vol, 2', North-Holland Publishing Co., Amsterdam, pp. 1281-1289, 1965

11 F.D. Seward, Phys. Rev, 1962, 126, 335-340

12 G.J. Lutz, Anal. Chem., 1969, 41, 424-427

13 C. Engelmann, J. Radioanal. Chem., 1970, 6, 399-412

14 Report of Committee II on Permissible Dose for Internal Radiarion (1959), I.C.R.P. Publication No. 2, published by Pergamon Press for the International Commission on Radiological Protection. 